\title{
AC 2007-3100: INNOVATIVE USE OF A RESEARCH REACTOR FOR INTERDISCIPLINARY ENGINEERING EDUCATION
}

John White, University of Massachusetts-Lowell

Leo Bobek, University of Massachusetts- Lowell 


\section{Innovative Use of a Research Reactor for Interdisciplinary Engineering Education}

\section{Introduction}

Over the last few years, the research reactor facility at the University of Massachusetts-Lowell (UMLRR) has developed capability to perform live experiments and deliver archived reactor operations data via a web-based interface to remote users. ${ }^{1-3}$ Access to this capability is available through the nuclear101.com educational website and the UMLRR Online link, ${ }^{4}$ which were originally set up as a resource for students, instructors, and working professionals interested in the nuclear engineering field. This capability was designed specifically to promote and enhance the use of the UMass-Lowell research reactor (UMLRR) within a much wider nuclear engineering educational community. The UMLRR has been a terrific educational resource for the students at UMass-Lowell for many years and, through this website, the goal was to share this rather unique resource beyond the physical boundaries of UMass-Lowell -- with, of course, a focus on nuclear engineering education. However, our experience over the last three years has indicated that the overall system can also be used successfully by a much wider base of engineering students with no background or specific interest in nuclear systems.

Within this non-nuclear context, the reactor core is simply treated as a variable heat source, whose energy can be removed by either natural or forced convection. The core is contained within a large pool of water which is used as both a heat sink and as a source of shielding for the core. The facility has a primary and secondary cooling system that includes primary and secondary pumps, a shell and tube heat exchanger, and a cooling tower for final discharge of the waste energy to the environment. The system is fully instrumented with over $40 \mathrm{web}$-accessible indicators (including core power level, primary and secondary flow rates, various temperature values, device on/off status indicators, etc.) that give a continuous picture of the overall condition of the system. Thus, the reactor facility represents a perfect scale model of a modern industrial plant with many of the same components and energy transport processes that can be found in any plant. This facility is rather unique within the educational community and it has the potential to provide a wide variety of educational opportunities and real-life learning experiences that are not readily available at most institutions.

This paper first describes the physical plant layout and main system components and discusses the overall web-accessible reactor laboratory system that has evolved over the last few years. By way of illustration, two specific cases are then highlighted: an introductory energy balance laboratory that has been conducted for several groups of freshman Chemical Engineering students, and a pool heat-up experiment that was used as the basis for a project in an Engineering Differential Equations course. Both these examples focus on the energy transfer and transport mechanisms that are an integral part of the reactor facility. The readily available data allow one to illustrate a number of fundamental concepts of interest to each course using real information from an operating facility -- and the real-world nature of these applications seems to really motive the students. The purpose of these examples is to highlight how the UMass-Lowell 
research reactor can be used as a general web-based laboratory tool for educating a broad range of engineering students. The ultimate goal here is to make a wider audience aware of this potential resource and to encourage collaboration with other institutions. The mission of our distance education project within the reactor facility is still to share this rather unique resource beyond the physical boundaries of UMass-Lowell, but the focus now extends well beyond the Nuclear Engineering field to include most other engineering disciplines.

\section{Facility Overview and Remote Accessibility}

The UMass-Lowell research reactor (UMLRR) is an open-pool reactor facility that is used for training and a variety of research activities. The reactor core, which is the source of neutrons, gamma rays, and thermal energy, all generated from the nuclear fission and capture process, is physically quite small. The core itself, which is suspended by a support system connected to a movable bridge, is located near the bottom of a large pool of water, contained within thick reinforced concrete walls. The large pool provides a heat sink for the energy generated within the core, and both the water and concrete walls provide radiation shielding so that no neutron or gamma radiation can escape. The pool surface is open to the atmosphere inside a containment building, where energy exchange via evaporation, convection, and radiation heat transfer can occur. A view of the pool surface, the support bridge, the upper portion of the core support structure, the control drive system, etc. is given in Fig. 1.

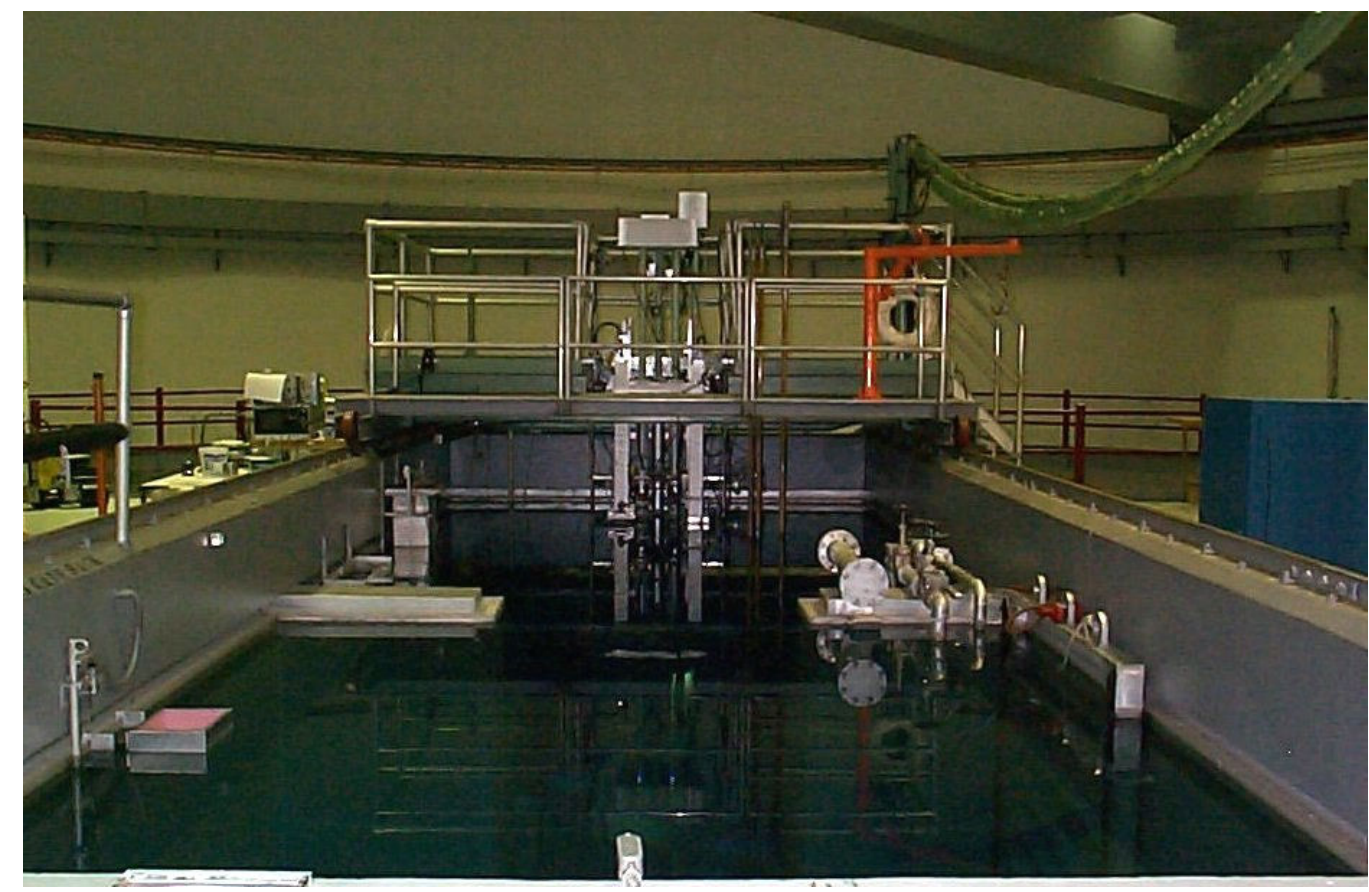

Fig. 1 View of pool surface, support bridge, and the upper core support structure.

The reactor can operate in either forced or natural convection mode -- with current thermal power limits set at $1000 \mathrm{~kW}$ and $100 \mathrm{~kW}$ in forced convection mode and natural convection mode, respectively. For normal operation with forced convection, the primary coolant system removes energy from the core and pool through a U-tube heat exchanger to the secondary-side cooling tower, which eventually releases the waste energy to the outside atmosphere. In natural 
convection mode, energy from the core simply heats up the pool water, which is eventually dissipated through the pool surface to the containment atmosphere.

In the UMLRR control room (see Fig. 2), a series of personal computers with touch-screen displays give the reactor operations staff access to a modern control and data acquisition system. The operators can view instrument readings, plot trends using real-time or historical data, view and acknowledge alarms, and modify and control plant operations. Almost all the process variables within the UMLRR (power level indicators, various temperatures, flow rates, pressures, conductivity measurements, control blade position indicators, on/off status of various motors, valves, fans, etc.) are available for realtime display, data trending, and archival storage.

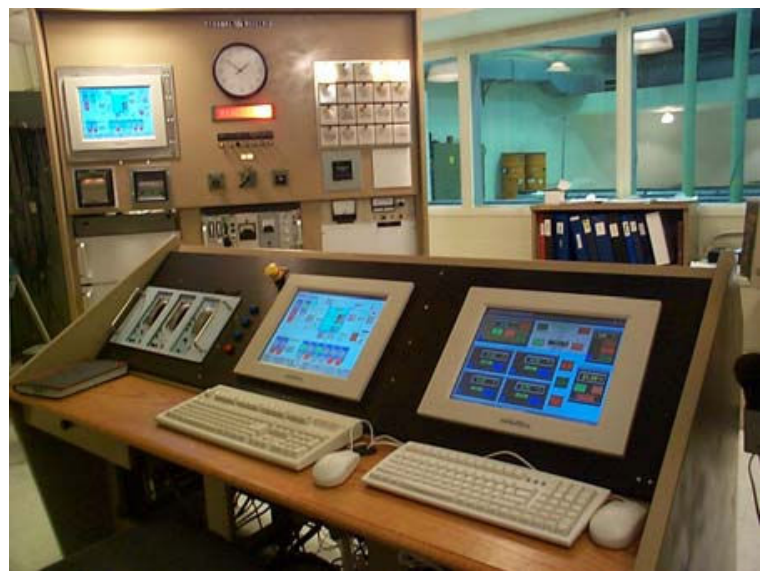

Fig. 2 View of reactor control room.

This same look and feel, without control capability, is also available for educational purposes for remote users via a simple web browser interface. This was accomplished using a standard personal computer to act as a web server along with the use of a special purpose software package that receives data from the control room computers and then distributes it in a webbased format. In particular, this real-time web-broadcasting capability is made possible by InduSoft Web Studio ${ }^{5}$ (IWS), a supervisory control and data acquisition (SCADA) package donated to UMass-Lowell by InduSoft Ltd. This software tool was used to create a series of screens that allow a user to observe most of the same real-time and historical information that is accessible to the reactor operators within the UMLRR control room.

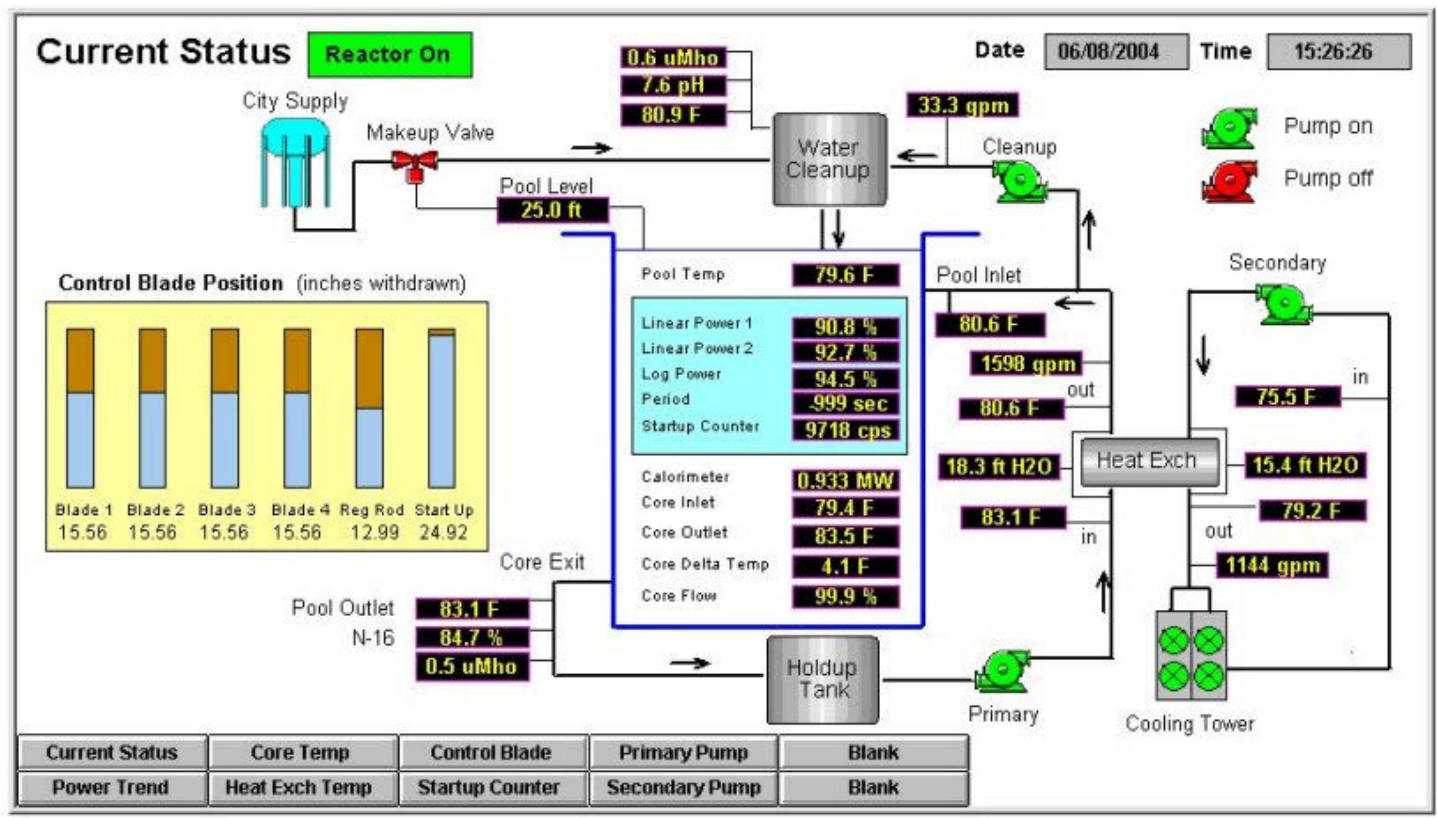

Fig. 3 Main status screen for web-based users showing the state of various plant sensors. 
The main user interface that is presented after login, as shown in Fig. 3, contains a rough schematic representation of the component configuration and coolant flow paths within the UMLRR. The diagram has a large pool containing the core in the center of the window and it shows the major primary and secondary coolant loop components (heat exchanger, cooling tower, various pumps and fans that control the energy removal process) and, of course, the control blades that are used to control the fission process in the reactor. During high power operation $(>100 \mathrm{~kW})$, primary coolant flow is from the pool, down through the core, through the primary piping, holdup tank, and heat exchanger, and back into the pool. The secondary coolant loop removes energy from the primary coolant within the heat exchanger, and releases it to the environment via the cooling towers. A make-up line is also available to maintain the proper liquid level in the pool, as needed. Finally, a cleanup loop containing a demineralizer and water softener -- used to maintain water purity -- is also shown. This main screen has more than 30 real-time indicators that show the current status or numerical value for most of the important plant parameters (power level, flow rates, temperatures, on/off indicators, etc.).

In addition to the main screen that shows the current status of the facility, a number of trend plots are also available that show how a particular parameter has changed over time. The user can select which parameter set to view using the buttons on the bottom of the Current Status screen. For example, a typical screen showing the various core and pool temperatures from a particular live online training session from Oct. 2006 is displayed in Fig. 4. This is typical of the each of the trend screens available. Note, in particular, that each of these screens has options for turning on and off selected curves, for activating the scale for each curve, for manually adjusting the min and max values, etc., as needed. The user can also stop/start the real-time data view (upper left corner), change the date, time, and duration of the data viewed on the screen, as well as modify a number of other interactive entries. This graphical user interface (GUI) gives each user sufficient control over what data are viewed and how the data are presented -- and each remote user has individual control over their specific environment.

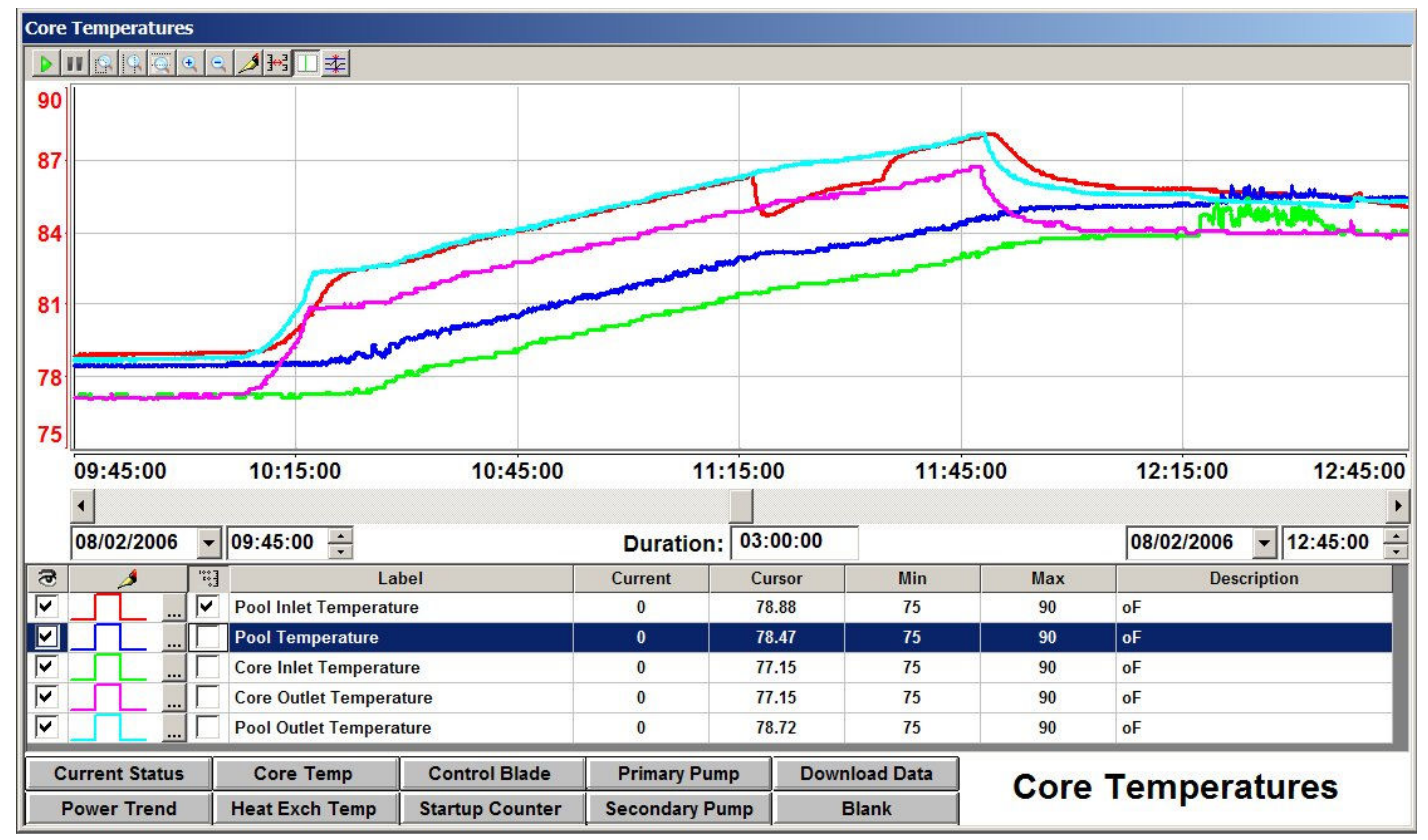

Fig. 4 Typical trend screen showing various user options. 
Real-time web conferencing capability via the Centra Live package ${ }^{6}$ is also available as part of the University's distance education infrastructure, and this tool has greatly improved the communication and interaction among all the sites involved in a particular online lab. In a typical live session with multiple sites, each student or group of students would be in a remote computer lab equipped with speakers and microphones. The lab facilitator would be at another remote site with similar equipment and possibly an inexpensive webcam and, of course, the reactor control room would be online with similar, but more robust capability. All the groups would be connected via a Centra e-meeting, with the facilitator and the reactor operators acting as presenters and the various groups of students as participants. Each group would also have the UMLRR Online application running within a browser window. During the live synchronous lab, the online students interact with the reactor plant through the lab facilitator and reactor operators by observing the real-time data, answering questions concerning current and future behavior, and making decisions and suggestions of how to proceed with a particular experimental sequence. Note, however, at this time, that only the reactor operations staff can modify existing conditions within the facility -- the Indusoft Web Studio application is set up to only allow the remote users to view the plant data, not to control facility operation!

After a live lab, the students can continue to access the data from a particular experiment via UMLRR Online for up to 30 days so that additional data processing and analysis can be done, as needed for a particular project or assignment. In addition, after an experiment has been completed, a user can also download the current daily history file to his or her local machine for additional offline processing -- and a set of Matlab codes are available for download from the nuclear101.com website to assist in the local post-processing step. All these tools give the distance learner essentially the same capability as a student physically located at UMass-Lowell.

\section{Example Applications}

Two specific examples are used to illustrate the use of the UMLRR as a tool for distance learning in a variety of engineering courses. Both these examples focus on the energy transfer and transport mechanisms that are an integral part of the reactor facility (or any industrial plant). In the first case, the concept of steady-state energy balances is introduced to freshman Chemical Engineers by running the reactor for several hours at constant power with different levels of cooling (by varying the on/off status of the secondary pumps and fans). The students are asked to record temperature and flow data for the core, pool, and heat exchanger at various times and to verify some simple quasi steady-state energy balance relationships that are derived for these particular systems. In the second example, a pool heat-up experiment is used as the basis for a project in an Engineering Differential Equations course, with a focus on solving and interpreting the solution of the $1^{\text {st }}$-order differential equation associated with a real-world application. The students are asked to perform an energy balance on the UMLRR pool with different energy loss approximations, solve the resultant first order differential equations, compare their results to the experimental data, and make recommendations concerning the adequacy of the various models. The energy balance experiments are run live but, for the pool heat-up project, the DE students simply access the archived experimental data from the course website. Both reactor-based experiments have proved to be quite successful in getting these students more involved with the subject matter under study. 
General Energy Balances Lab: The energy balance lab is run as part of the $2^{\text {nd }}$ semester freshman Introduction to Engineering course. In particular, in the spring semester, the freshman Chemical Engineering students at UMass-Lowell are introduced, via a series of 2-week hands-on modules, to several of the topics that will be discussed in further detail within their subsequent engineering science and design courses over the next several years. Each week includes a 1-hour lecture followed by a set of 2-hour labs with groups of 8-12 students in each section. The Energy Balances in Nuclear Systems module focuses on the concept of general balance relationships in all engineering analyses (i.e. rate of change = production rate - loss rate), with special focus on steady state energy balances in power generation and energy conversion systems. The first week lecture overviews the key components of nuclear systems (reactor core, steam generator, turbine, condenser, etc.) and the energy flow paths among these components in typical power and research reactor systems. During the lab, after a brief overview of the specific plant layout for the UMLRR, the students are given some basic information about the facility (power level, pool volume, coolant flow rates, etc.) and they are asked to do a set of preliminary calculations that involve units conversion and some simple energy balance concepts (i.e. energy storage capacity, core $\Delta \mathrm{T}$, pool heat-up rate, etc.). A worksheet is given and the students break into small groups to perform the desired computations specific to the UMLRR. The instructor and teaching assistant (TA) work with the student groups, giving specialized help as needed. Any computations not completed during the 2-hour lab are finished as a group homework assignment.

In the second week of the module, the lecture overviews additional energy balance relationships for the core, pool, and heat exchanger systems within the UMLRR. The preliminary calculations from the first week are reviewed and an outline of the computations that will be required for the subsequent lab is given. In the lab portion, the students observe actual reactor operation using the web-based UMLRR Online application to present the live reactor data over the internet (as discussed in detail above). From the Department Computer Lab, the students record various flow rates and temperature measurements for a variety of operating conditions, and use these to validate the series of quasi steady-state energy balance relationships developed and discussed in the previous lecture. Again, a worksheet is given and the calculations are done in small groups with individual help from the instructor and TA, as needed. Periodically during the lab (about every hour or so for 4-5 hours) the reactor staff are requested to change the current conditions and the students are asked to predict what will occur. In particular, the secondary pump and the two fans in the cooling tower are switched on/off at different times to allow varying amounts of energy removal from the system. Thus, during different periods of time, the various temperature indicators throughout the system show that the system is either heating up or cooling down at various rates depending on the amount of cooling provided by the secondary cooling loop. The student calculations focus on really understanding the key concepts associated with quasi-static energy balances within an actual operating plant. The students only complete about half of the worksheet during the in-class lab, and they are requested to finish the remaining computations and analyses as a group homework project (note that the history data from the UMLRR Online application remains accessible online for several weeks).

The actual worksheets used in the Spring 2006 module (reformatted slightly to save space) are included as an Appendix to this paper. In addition, an outline of the reactor operations sequence and some of the actual experimental data are summarized within Table 1 and Figs. 5 and 6 , 
respectively. Note that, since the focus here was on steady state energy balances, only the data for the quasi-steady time periods were used in the student analyses. These periods occur after the transient associated with the pump and fan state changes has passed, and all of the temperatures within the system either rise or fall at approximately the same rate. These quasisteady periods are easy to identify in Figs. 5 and 6 for the four sets of cooling conditions established for this experiment (see Table 1 for a description of the four cooling states).

Table 1 Summary of reactor operations during the experiment of March 9, 2006.

\begin{tabular}{|c|l|c|}
\hline $\begin{array}{c}\text { Approximate } \\
\text { Start Time }\end{array}$ & \multicolumn{1}{|c|}{ Description } & $\begin{array}{c}\text { Secondary } \\
\text { Cooling Rate }\end{array}$ \\
\hline $9: 45 \mathrm{am}$ & $\begin{array}{l}\text { Reactor brought to about } 85 \% \text { rated power (i.e. 0.85 MW) } \\
\text { with the secondary coolant pump off. The system was } \\
\text { operated for over 1 hour in this mode. }\end{array}$ & near zero level \\
\hline $11: 05 \mathrm{am}$ & $\begin{array}{l}\text { The secondary pump was turned on but both fans were off. } \\
\text { This relatively low cooling rate was maintained for about } \\
1 \text { hour. }\end{array}$ & $\begin{array}{c}\text { low intermediate } \\
\text { level }\end{array}$ \\
\hline $12: 05 \mathrm{pm}$ & $\begin{array}{l}\text { Cooling Fan \#1 was turned on, but Fan \# 2 was still off. } \\
\text { This provided a higher level of cooling than the previous } \\
\text { phase of the experiment. This state was maintained for } \\
\text { about } 1 \text { hour. }\end{array}$ & $\begin{array}{c}\text { high intermediate } \\
\text { level }\end{array}$ \\
\hline $1: 05 \mathrm{pm}$ & $\begin{array}{l}\text { Fan \#2 was turned on to increase the rate of energy } \\
\text { removal from the system to its highest level (full cooling } \\
\text { rate with secondary pump and both fans turned on). This } \\
\text { state was maintained for about 1.5 hours. }\end{array}$ & highest level \\
\hline
\end{tabular}

The detailed calculations for this experiment are not given here. However, if one follows the requested worksheet calculations in the Appendix, one can validate (approximately) a variety of statements concerning several overall energy balances for this system, such as:

1. Based on flow rate and core $\Delta \mathrm{T}$ measurements (CoreTout - CoreTin), the core power level was about $0.78 \mathrm{MW}$. This compared reasonably well to the measured average power of about $0.85 \mathrm{MW}$ considering the small $\Delta \mathrm{T}$ and the uncertainty involved in getting the required data from the trend plots.

2. Assuming negligible energy losses in the pool when the secondary is off, the pool heat-up rate should be related to the core power output during this interval. Using the PoolTave indicator, the measured value of $\Delta$ PoolTave $/ \Delta t \approx 0.067 \mathrm{~F} / \mathrm{min}$ leads to a power level of 0.75 MW (again this is within the measurement uncertainty).

3. During the various time intervals with different cooling rates, the rate of change of the pool temperature was consistent (approximately) with the net energy removal rates from the pool. For example, for the last time interval with the maximum cooling rate, the temperature of the pool was decreasing at a rate of about $0.044 \mathrm{~F} / \mathrm{min}$-- which implies that about $0.53 \mathrm{MW}$ of power was being removed from the pool. However, during this time the core is adding about $0.85 \mathrm{MW}$ and the heat exchanger, based on the flow and $\Delta \mathrm{T}$ measurements across this component, was removing about $1.5 \mathrm{MW}$ of power. Clearly this balance is only approximate, but the net removal rate of $(0.85-1.5) \mathrm{MW}=-0.65 \mathrm{MW}$ is reasonably close to the value of $-0.53 \mathrm{MW}$ obtained from the slope of the PoolTave profile. 


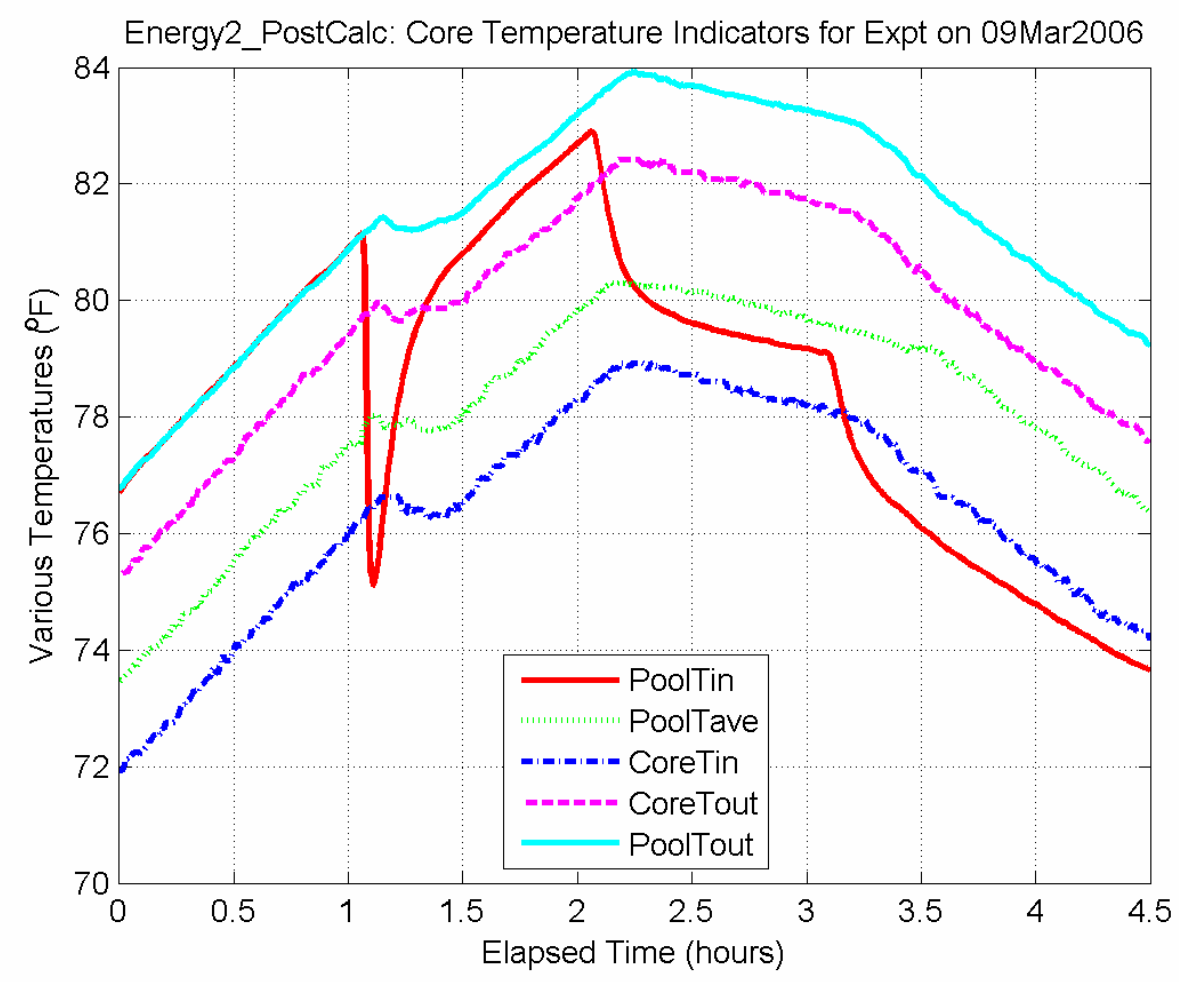

Fig. 5 Selected core temperatures during the experiment of March 9, 2006.

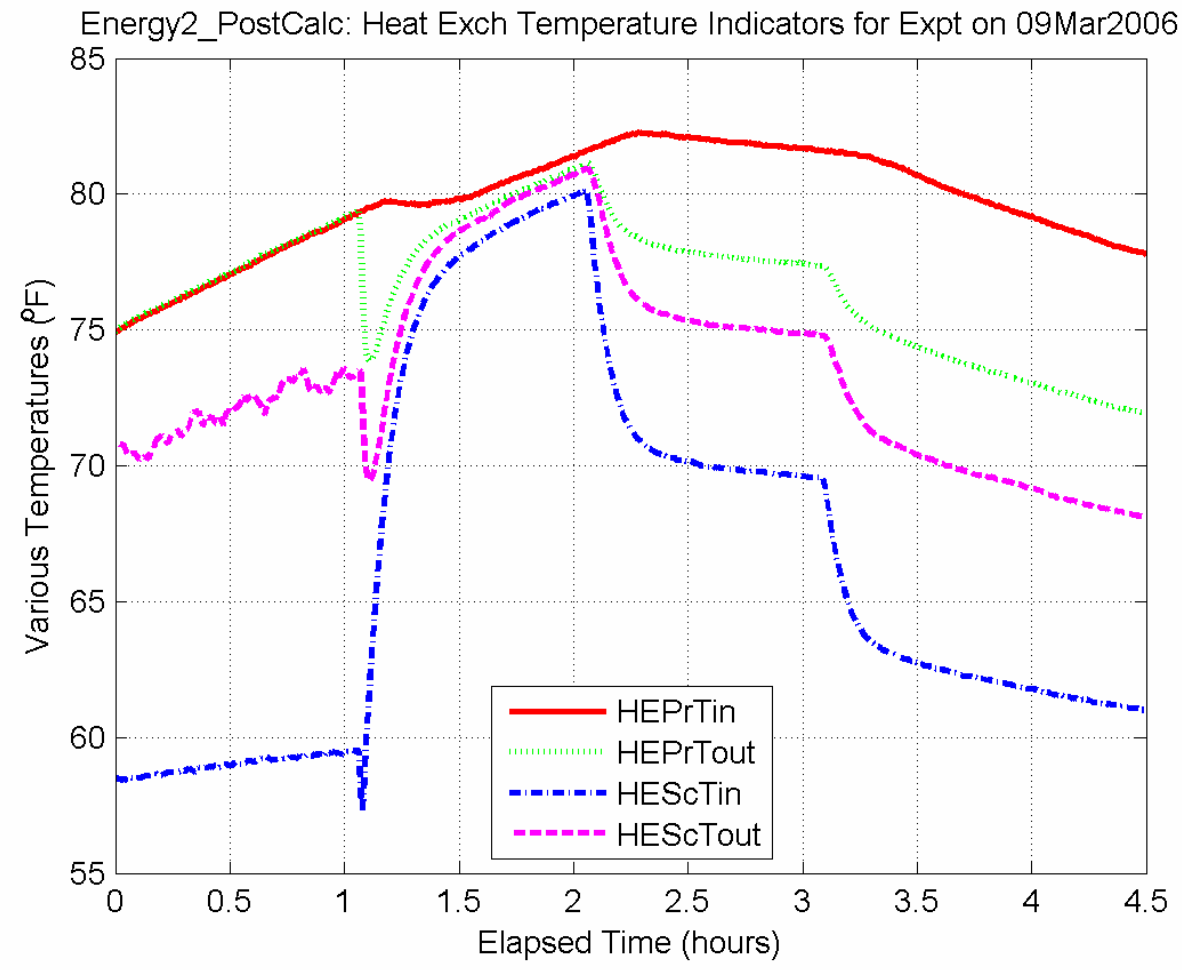

Fig. 6 Heat exchanger temperatures during the demo of March 9, 2006. 
A number of additional balance relationships, similar to the above examples, are also discussed (see the Appendix for the detailed calculations that are requested). Overall, this module gives the students a good introduction to a variety of energy balance concepts and they get to see and work with real data (with its inherent uncertainty) from an operational industrial plant.

Pool Heat-Up Project for DE Course: Once an engineering student has been exposed to a course in differential equations, one can start discussing the dynamics of engineering systems and processes within the curriculum. In real systems, the plant dynamics usually offer more interesting and more challenging phenomena for discussion, and a wide range of modeling and simulation projects can be used as educational tools for illustrating and understanding the transient behavior of these systems. Within this context, the UMLRR is again an excellent source of real-world dynamic data for an operating plant. For example, the data presented in Figs. 5 and 6 for the above illustration clearly show some interesting dynamic behavior, although only the quasi steady-state data were used as part of the Energy Balances class project. A straightforward application that makes use of the plant's dynamic behavior, for example, might be a simple modeling project within an applications-oriented differential equations course. In particular, several mathematics and engineering faculty at UMass-Lowell have collaborated to develop an Engineering Differential Equations course designed specifically to put a little more focus on modeling and applications within the first differential equations course. Within this course, extra emphasis is placed on the mathematical modeling of physical systems from basic principles (i.e. basic mass, energy, particle, and force balances, etc.), on both the analytical and numerical solution to initial value problems (IVPs), and on the implementation, visualization, and analysis of the physical solutions within the Matlab package.

In addition to a number of applications-oriented homework and exam problems, at least one comprehensive group project is also required as part of the Engineering DE course at UMassLowell. In Spring 2005, a pool heat-up experiment in the UMLRR was used as the basis for the first course project. As part of the project, the students are asked to consider a pool energy balance with different energy loss approximations, solve the first order differential equations that are developed, compare their results for a portion of the simulation to some experimental data from the UMLRR, and draw conclusions concerning predictive capability and overall adequacy of the various models. The model simulates reactor operation at full power for about 8 hours with no forced cooling. During the early part of the simulation, the pool temperature increases nearly linearly. After a few hours, however, as the pool temperature rises, the heat loss via convection and evaporation from the pool surface can become important, and a decrease in the pool temperature gradient might be observed depending upon the heat loss coefficients used in the model. The students compared the first part of their simulations to actual data from a previous reactor run, and they used the solution of the DE at later times to predict the future longer-term behavior.

As for the previous example, a complete solution of the Pool Heat-Up Project is not given here. However, a copy of the full project write-up is included in the Appendix to this paper and some summary results from the instructor's simulations are presented in Figs. 7 and 8. The results in Fig. 7, in particular, compare the simulation model prediction to the experiment data for the first hour or so of operation, when the pool temperature is close to the containment air temperature. During this period, the simulation matches the experimental data almost exactly (especially when 
the small losses in the primary loop are treated), and the result is independent of the heat transfer coefficient used during the simulation. For longer run times, however, using the correct heat transfer coefficient is essential as shown in Fig. 8. Unfortunately, experimental data were not available for comparison here since the actual pool is not usually allowed to get much above a temperature of $95 \mathrm{~F}$. However, plans are currently underway to modify plant conditions somewhat so that a more significant surface loss component can be measured with reasonable pool temperatures. Thus, a modified version of this project may be available in the near future.
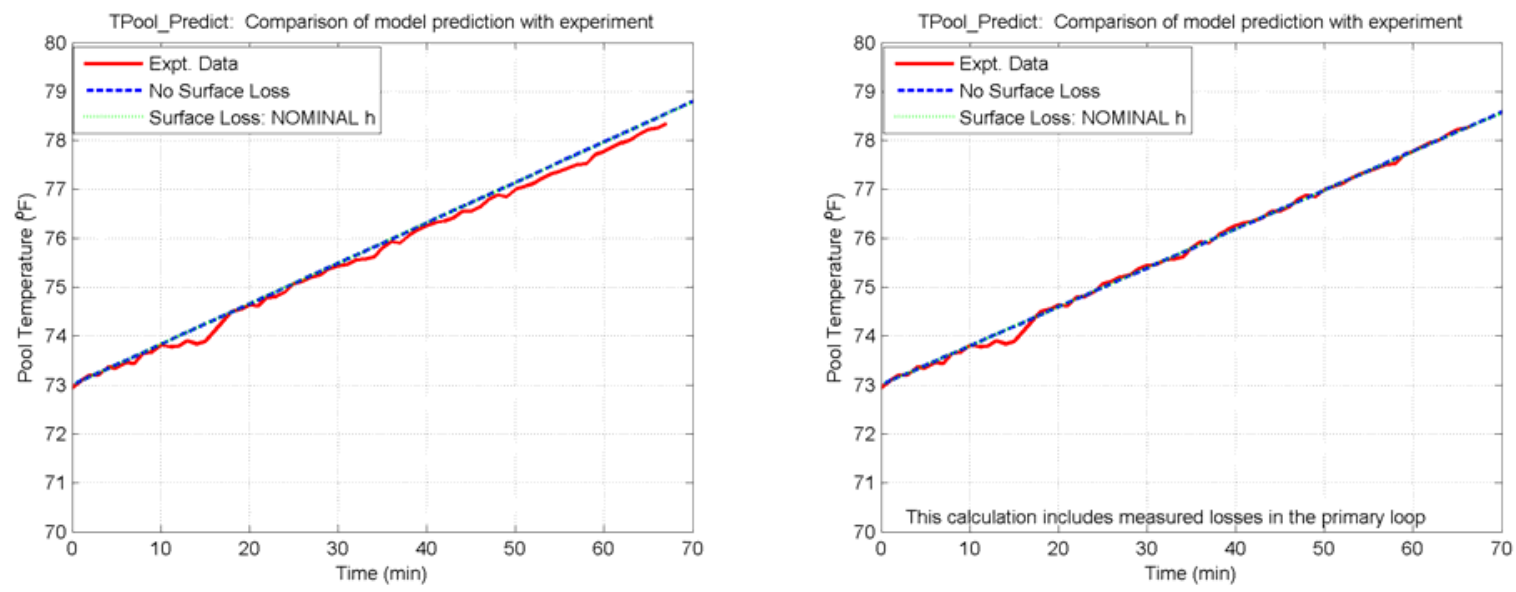

Fig. 7 Results from the pool heat-up simulation versus experimental data.
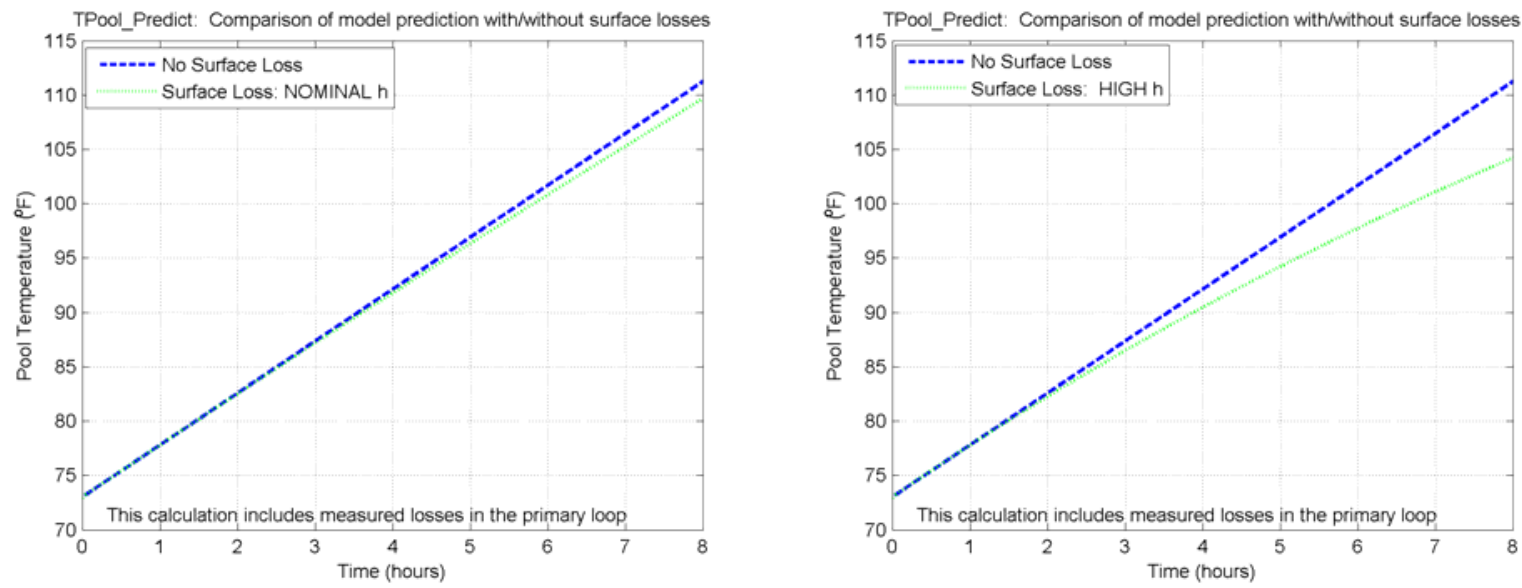

Fig. 8 Variation of pool heat-up rates for different heat transfer coefficients.

Feedback on this project in the DE class has been very positive. Most students indicate that they definitely prefer to work with real systems, rather than idealized textbook problems, and that the learning experience is much more meaningful and lasting. Based on this informal feedback and the variety of interesting dynamics data available from the UMLRR, additional related projects are planned for future DE classes (and other Fluid Mechanics, Heat Transfer, and general Mathematical Modeling courses). All this information will be made available on the nuclear101.com website as new modules or projects are developed so that other interested institutions can also benefit from these real-world learning experiences. 


\section{The Future...}

The distance education initiative at the UMass-Lowell research reactor (UMLRR) was originally focused on providing remote access to real-time and archived research reactor data for use in other nuclear engineering educational programs around the globe. However, as new capabilities were implemented over the last few years, it became apparent that this initial mission could easily expand to include most other engineering disciplines (such as Chemical Engineering, Mechanical Engineering, Systems Engineering, etc.). The real goal of this paper is to make the various engineering disciplines, who normally don't think about a nuclear research reactor as a key teaching and learning tool within their respective fields, aware of the UMLRR as a potential resource for some unique learning opportunities for their students. The examples given here illustrate the type of problems that can be addressed using a real industrial plant within an academic setting. Since no special equipment or software is required -- just access to the internet through a standard web browser -- any institution can take advantage of this resource. In the coming years, we certainly hope to expand our capabilities and to increase the number and variety of learning experiences available through the nuclear101.com website and the UMLRR Online link. However, our most immediate goal is to encourage more collaboration with other institutions interested in using the UMLRR as an online laboratory for their engineering students. Through these collaborations we hope that the future brings a wide range of new ideas, enhanced capabilities, and more innovative learning experiences for all our students.

\section{Acknowledgements}

This work was funded in part by a Department of Energy (DOE) grant through the Reactor Sharing Program at UMass-Lowell (Grant \# DE-FG07-02ID14378). InduSoft Ltd. donated the InduSoft Web Studio software ${ }^{5}$ used in this project as the web interface between the reactor data acquisition system and the remote user.

\section{References}

1. J. R. WHITE, A. JIRAPONGMED and L. M. BOBEK, "A Web-Based System for Access to Real-Time and Archival Research Reactor Data”, Trans. Am. Nuc. Soc. (June 2004).

2. P. JAIN, S. MARKIDIS, B. G. JONES, RIZWAN-UDDIN, J. R. WHITE, and L. M. BOBEK, "Web-casting of Nuclear Reactor Experiments", Trans. Am. Nuc. Soc. (Nov. 2006).

3. J. R. WHITE and L. M. BOBEK, "Reactor Operations Training via Web-Based Access to the UMass-Lowell Research Reactor," Proceedings of Conference on Nuclear Training and Education, Jacksonville, Florida (Feb. 2007).

4. The Nuclear101 website and UMLRR Online prototype, www.nuclear101.com/.

5. InduSoft Web Studio, www.indusoft.com/.

6. Centra Live for e-Meetings, http://www.saba.com/

\section{Appendices}

The following several pages contain the student handouts used with the two projects discussed in this paper. Note that the two worksheets for the Energy Balances Laboratory were reformatted slightly to save space in this paper. 


\section{Introduction to Engineering II \\ Preliminary Calculations for \\ Energy Balance Calculations for the UMLRR}

\section{Base Data:}

Water properties: $\quad \rho=1000 \mathrm{~kg} / \mathrm{m}^{3}$

$\mathrm{c}_{\mathrm{p}}=4.2 \mathrm{~kJ} / \mathrm{kg}^{\circ}{ }^{\circ} \mathrm{C}$

UMLRR data:

$\mathrm{V}=76000$ gal (pool volume)

$\mathrm{P}_{\mathrm{th}}=1 \mathrm{MW}$ (rated core power)

$\mathrm{Q}_{\mathrm{p}}=1650 \mathrm{gal} / \mathrm{min}$ (primary coolant flow rate)

$\mathrm{Q}_{\mathrm{s}}=1550 \mathrm{gal} / \mathrm{min}$ (secondary coolant flow rate)

\section{Conversion Factors:}

Volume: $\quad 1 \mathrm{~m}^{3}=264 \mathrm{gal}$

flow rate: $\quad 1 \mathrm{~m}^{3} / \mathrm{s}=15850 \mathrm{gal} / \mathrm{min}$

power: $\quad 1 \mathrm{~W}=1 \mathrm{~J} / \mathrm{s}$

temperature change: $\quad 5^{\circ} \mathrm{C}=9{ }^{\circ} \mathrm{F}$

\section{Preliminary Calculations (be careful with units):}

mass of water in pool $(\mathrm{kg})$, where $\mathrm{m}=\rho \mathrm{V}$ :

pool energy storage capacity $\left(\mathrm{MJ} /{ }^{\circ} \mathrm{C}\right)$, where $\mathrm{C}=\mathrm{mc}_{\mathrm{p}}$ :

pool energy storage capacity $\left(\mathrm{MJ} /{ }^{\circ} \mathrm{F}\right)$ [since measured temperatures are in $\left.{ }^{\circ} \mathrm{F}\right]$ :

primary side mass flow rate $(\mathrm{kg} / \mathrm{s})$, where $\dot{\mathrm{m}}_{\mathrm{p}}=\rho Q_{\mathrm{p}}$ :

secondary side mass flow rate $(\mathrm{kg} / \mathrm{s})$, where $\dot{\mathrm{m}}_{\mathrm{s}}=\rho \mathrm{Q}_{\mathrm{s}}$ :

estimate the steady-state full-power core $\Delta \mathrm{T}\left({ }^{\circ} \mathrm{F}\right)$ at full flow conditions :

$$
\mathrm{P}_{\text {core }}=\left.\dot{\mathrm{m}}_{\mathrm{p}} \mathrm{c}_{\mathrm{p}}\left(\mathrm{T}_{\text {out }}-\mathrm{T}_{\text {in }}\right)\right|_{\text {core }}=\left.\dot{\mathrm{m}}_{\mathrm{p}} \mathrm{c}_{\mathrm{p}} \Delta \mathrm{T}\right|_{\text {core }}
$$

maximum pool heat-up rate $\left({ }^{\circ} \mathrm{F} / \mathrm{min}\right)$ assuming no energy removed from the core (no losses) :

$$
\frac{\mathrm{dE}_{\text {pool }}}{\mathrm{dt}}=\mathrm{mc}_{\mathrm{p}} \frac{\mathrm{dT}_{\text {pool }}}{\mathrm{dt}}=\mathrm{P}_{\text {core }}-\mathrm{P}_{\text {removed }} \quad \text { or }\left.\quad \frac{\mathrm{dT}_{\text {pool }}}{\mathrm{dt}}\right|_{\max }=\frac{1}{\mathrm{mc}_{\mathrm{p}}} \mathrm{P}_{\text {core }} \quad \text { (for no losses) }
$$

at the maximum pool heat-up rate, estimate the time ( $\mathrm{min})$ needed to heat the pool by $10{ }^{\circ} \mathrm{F}$ : 


\section{Introduction to Engineering II}

Worksheet for Spring 2006

Energy Balance Calculations for the UMLRR

Date of Operation:

Team Members:

Base Data:

Water properties: $\rho=1000 \mathrm{~kg} / \mathrm{m}^{3}$

$\mathrm{c}_{\mathrm{p}}=4.2 \mathrm{~kJ} / \mathrm{kg}_{-}{ }^{\circ} \mathrm{C}$

UMLRR data:

$\mathrm{V}=76000$ gal (pool volume)

$\mathrm{P}_{\mathrm{th}}=1 \mathrm{MW}$ (rated core power)

$\mathrm{Q}_{\mathrm{p}}=1650 \mathrm{gal} / \mathrm{min}$ (nominal primary coolant flow rate)

$\mathrm{Q}_{\mathrm{s}}=1550 \mathrm{gal} / \mathrm{min}$ (nominal secondary coolant flow rate)

\section{Conversion Factors:}

volume: $\quad 1 \mathrm{~m}^{3}=264 \mathrm{gal} \quad$ flow rate: $\quad 1 \mathrm{~m}^{3} / \mathrm{s}=15850 \mathrm{gal} / \mathrm{min}$

power: $\quad 1 \mathrm{~W}=1 \mathrm{~J} / \mathrm{s} \quad$ temperature change: $5{ }^{\circ} \mathrm{C}=9{ }^{\circ} \mathrm{F}$

\section{Results from Preliminary Calculations:}

mass of water in pool $(\mathrm{kg})$ :

$$
\mathrm{m}=\rho \mathrm{V}=2.88 \times 10^{5} \mathrm{~kg}
$$

pool energy storage capacity $\left(\mathrm{MJ} /{ }^{\circ} \mathrm{F}\right)$ :

$\mathrm{C}=\mathrm{mc}_{\mathrm{p}}=671.7 \mathrm{MJ} /{ }^{\circ} \mathrm{F}$

primary side mass flow rate $(\mathrm{kg} / \mathrm{s})$ :

$\dot{\mathrm{m}}_{\mathrm{p}}=\rho \mathrm{Q}_{\mathrm{p}}=104.1 \mathrm{~kg} / \mathrm{s}$

secondary side mass flow rate $(\mathrm{kg} / \mathrm{s})$ :

$$
\dot{\mathrm{m}}_{\mathrm{s}}=\rho Q_{\mathrm{s}}=97.8 \mathrm{~kg} / \mathrm{s}
$$

estimate the full-power core $\Delta \mathrm{T}\left({ }^{\mathrm{o}} \mathrm{F}\right)$ :

$$
\left.\Delta \mathrm{T}\right|_{\text {core }}=\frac{1}{\dot{\mathrm{m}}_{\mathrm{p}} \mathrm{c}_{\mathrm{p}}} \mathrm{P}_{\text {rated }}=4.1^{\circ} \mathrm{F}
$$

maximum pool heat-up rate $\left({ }^{\mathrm{o}} \mathrm{F} / \mathrm{min}\right):\left.\quad \frac{\mathrm{dT}_{\mathrm{pool}}}{\mathrm{dt}}\right|_{\max }=\frac{1}{\mathrm{mc}_{\mathrm{p}}} \mathrm{P}_{\text {rated }}=0.089{ }^{\circ} \mathrm{F} / \mathrm{min}$

estimate minimum time (min) needed to heat the pool by $10{ }^{\circ} \mathrm{F}$ : about $112 \min$ (nearly 2 hrs)

\section{Record the Current Environmental Conditions:}

temperature inside containment:

outside environment temperature:

is it a windy day?: 
Note: When taking data to perform the following calculations and to address the given questions, be sure to first record the time interval and temperatures and/or flow rates (i.e. the raw data) of interest. Then, you can proceed with the appropriate computations using the recorded experimental data.

\section{Core Balance:}

$$
\frac{\mathrm{dE}_{\text {core }}}{\mathrm{dt}}=\left.\dot{\mathrm{m}}_{\mathrm{p}} \mathrm{c}_{\mathrm{p}}\left(\mathrm{T}_{\text {in }}-\mathrm{T}_{\text {out }}\right)\right|_{\text {core }}+\mathrm{P}_{\text {core }}
$$

and, at steady state, we have

$$
\mathrm{P}_{\text {core }}=\left.\dot{\mathrm{m}}_{\mathrm{p}} \mathrm{c}_{\mathrm{p}}\left(\mathrm{T}_{\text {out }}-\mathrm{T}_{\text {in }}\right)\right|_{\text {core }}=\left.\dot{\mathrm{m}}_{\mathrm{p}} \mathrm{c}_{\mathrm{p}} \Delta \mathrm{T}\right|_{\text {core }}
$$

1. Record data for the primary flow rate and the measured core inlet and outlet temperatures at a particular time point. Now, with these data at some specific time, estimate the actual operating power level of the reactor using the above expressions.

2. From the Power Screen, estimate the actual operating power level? Does your result from Part \#1 make sense -- are your data consistent with the power indicators? Explain any differences...

\section{Pool Balance:}

$$
\frac{\mathrm{dE}_{\text {pool }}}{\mathrm{dt}}=\mathrm{mc}_{\mathrm{p}} \frac{\mathrm{dT}_{\text {pool }}}{\mathrm{dt}}=\left.\dot{\mathrm{m}}_{\mathrm{p}} \mathrm{c}_{\mathrm{p}}\left(\mathrm{T}_{\text {in }}-\mathrm{T}_{\text {out }}\right)\right|_{\text {pool }}+\mathrm{P}_{\text {core }}-\mathrm{P}_{\text {loss }}
$$

or

$$
\frac{\mathrm{dT}_{\text {pool }}}{\mathrm{dt}}=\left.\frac{\dot{\mathrm{m}}_{\mathrm{p}} \mathrm{c}_{\mathrm{p}}}{\mathrm{mc}_{\mathrm{p}}}\left(\mathrm{T}_{\text {in }}-\mathrm{T}_{\text {out }}\right)\right|_{\text {pool }}+\frac{1}{\mathrm{mc}_{\mathrm{p}}} \mathrm{P}_{\text {net }}
$$

where $\mathrm{P}_{\text {net }}$ is the net power generated within the pool (core generation rate - loss rate at surface).

1. From the Core Temperatures screen, carefully record the approximate change in pool temperature over some time interval (use $\Delta t \geq 10 \mathrm{~min}$ ) when the secondary side is OFF. Using these data, estimate the pool heat up rate, $\mathrm{dT}_{\text {pool }} / \mathrm{dt}$. Are your measurements consistent with the preliminary calculations for the maximum heat up rate done previously? Explain...

2. Now, use the pool inlet, average, and exit temperatures, as needed, to compute the pool heat up rate and to validate (approximately) the pool balance equation given above (assume no losses in your calculations) at various times throughout this experiment. Does everything make sense? Is the left hand side (LHS) and RHS of the equation approximately equal? Explain...

Perform and discuss these calculations for three different time periods, as follows:

a. when the secondary is ON, but both fans are OFF:

b. when the secondary is $\mathrm{ON}$, and Fan $\# 1$ is $\mathrm{ON}$

c. when the secondary is $\mathrm{ON}$, and both Fans \#1 and \#2 are $\mathrm{ON}$ 


\section{Heat Exchanger Balance:}

$$
\begin{array}{ll}
\text { primary side: } & \frac{\mathrm{dE}_{\mathrm{p}}}{\mathrm{dt}}=\left.\dot{\mathrm{m}}_{\mathrm{p}} \mathrm{c}_{\mathrm{p}}\left(\mathrm{T}_{\mathrm{in}}-\mathrm{T}_{\text {out }}\right)\right|_{\text {primary }}-\mathrm{HT}_{\mathrm{p}} \\
\text { secondary side: } & \frac{\mathrm{dE}_{\mathrm{s}}}{\mathrm{dt}}=\left.\dot{\mathrm{m}}_{\mathrm{s}} \mathrm{c}_{\mathrm{p}}\left(\mathrm{T}_{\mathrm{in}}-\mathrm{T}_{\text {out }}\right)\right|_{\text {sec ondary }}+\mathrm{HT}_{\mathrm{s}}
\end{array}
$$

where $\mathrm{HT}_{\mathrm{p}}$ is the heat transfer from the primary side and $\mathrm{HT}_{\mathrm{s}}$ is the heat transfer to the secondary side.

At steady state (or quasi steady state), we have

$$
\mathrm{HT}_{\mathrm{p}}=\left.\dot{\mathrm{m}}_{\mathrm{p}} \mathrm{c}_{\mathrm{p}}\left(\mathrm{T}_{\mathrm{in}}-\mathrm{T}_{\text {out }}\right)\right|_{\text {primary }} \quad \text { and } \quad \mathrm{HT}_{\mathrm{s}}=\left.\dot{\mathrm{m}}_{\mathrm{s}} \mathrm{c}_{\mathrm{p}}\left(\mathrm{T}_{\text {out }}-\mathrm{T}_{\mathrm{in}}\right)\right|_{\text {sec ondary }}
$$

and clearly, $\mathrm{HT}_{\mathrm{p}}$ should equal $\mathrm{HT}_{\mathrm{s}}$.

1. When the secondary pump is OFF, determine $\mathrm{HT}_{\mathrm{p}}$ and $\mathrm{HT}_{\mathrm{s}}$ (in units of MW). Do the data make sense? Explain...

2. When the secondary pump is $\mathrm{ON}$ and both fans are $\mathrm{OFF}$, estimate $\mathrm{HT}_{\mathrm{p}}$ and $\mathrm{HT}_{\mathrm{s}}$ (in units of $\mathrm{MW}$ ) from the measured data. Are the values of $\mathrm{HT}_{\mathrm{p}}$ and $\mathrm{HT}_{\mathrm{s}}$ approximately in balance? During the time interval of interest, are the overall temperatures increasing, decreasing, or relatively constant? Is this what you expected (in light of your results for the Pool Balance analysis)? Explain...

3. When the secondary pump is $\mathrm{ON}$ and Fan \#1 is $\mathrm{ON}$, estimate $\mathrm{HT}_{\mathrm{p}}$ and $\mathrm{HT}_{\mathrm{s}}$ from the measured data. Are the "quasi steady state" temperatures increasing, decreasing, or relatively constant? Discuss your results as in Part 2 above?

4. When the secondary pump and both Fans \#1 and \#2 are ON, repeat the above analyses. Explain your results -- is this what you expected? 


\section{Differential Equations (92.236)}

Project \#1 Spring 2005

\section{Energy Balance Calculations for Heat-Up of the UMLRR Pool}

\section{Background}

UMass-Lowell has a $1 \mathrm{MW}$ nuclear reactor (UMLRR) on campus that is used for training and a variety of research activities. The reactor core, where the energy is generated from the nuclear fission process, is quite small. The core itself is located near the bottom of a large pool of water (about 76000 gallons), contained within thick reinforced concrete walls. The large pool of water provides a heat sink for the energy generated within the core, and both the water and concrete walls provide radiation shielding so that no neutron or gamma radiation can escape. The pool surface is open to the atmosphere inside of containment, where energy exchange via evaporation, convection, and radiation heat transfer can occur (the $25 \mathrm{ft}$ of water above the core acts as radiation shielding in this direction).

The reactor can operate in either forced or natural convection mode. With forced convection, the primary coolant system normally removes energy from the core (and pool) through a heat exchanger to the secondary-side cooling tower, which eventually releases the waste energy to the outside atmosphere. The primary coolant flow rate in this mode is about $1600 \mathrm{gpm}$. In natural convection mode, energy from the core simply heats up the pool water, which is eventually dissipated through the pool surface to the containment atmosphere.

A simple conceptual sketch of the energy flows in the large UMLRR pool is shown in Fig. 1. This shows that energy can enter the pool via flow into the pool and via the internal energy generation associated with the fission process in the reactor core. Energy loss paths include the energy that is transported with the coolant leaving the system and via several heat transfer mechanisms (evaporation, convection, and radiation) at the pool surface. Note that, over relatively short periods of time, only negligible amounts of energy loss occurs through the thick concrete pool walls (so this is not shown in Fig. 1).

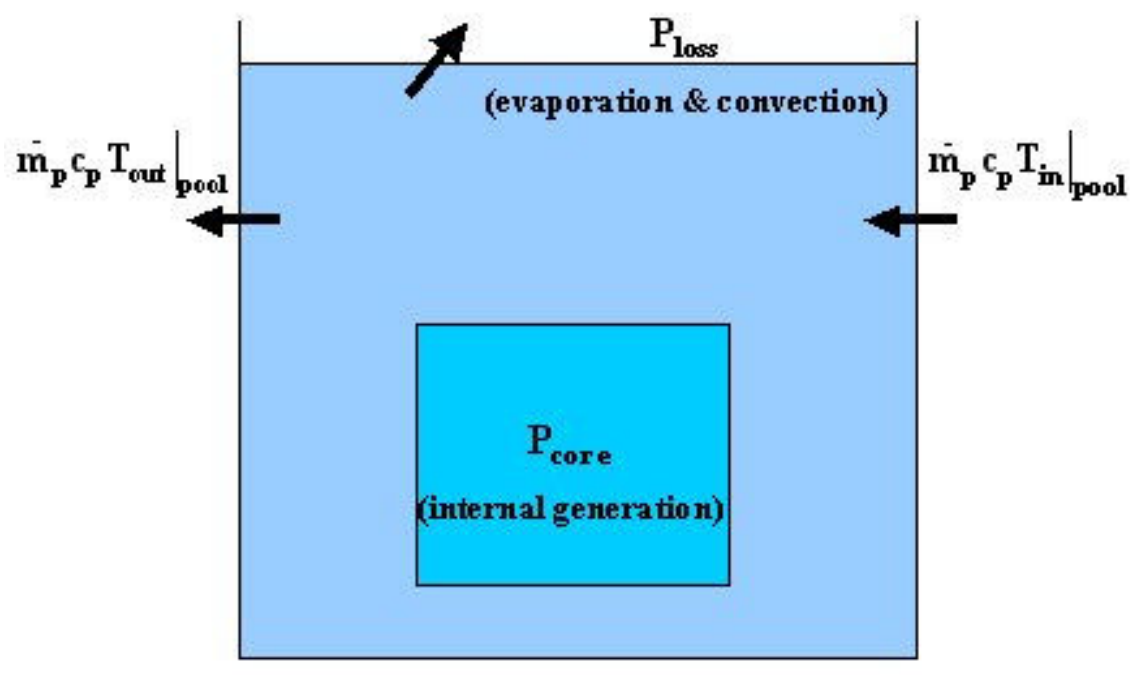

Fig. 1 Sketch showing the key energy transport paths in the UMLRR pool. 
With the energy generation and loss paths shown in Fig. 1, we can write an energy balance for the pool water, as follows:

$$
\begin{gathered}
\text { rate of change of } \\
\text { energy in pool }
\end{gathered}=\begin{gathered}
\text { net rate of energy } \\
\text { flow into the pool }
\end{gathered}+\begin{gathered}
\text { internal generation rate } \\
\text { of energy within the pool }
\end{gathered}-\begin{gathered}
\text { rate of energy loss at } \\
\text { surface of the pool }
\end{gathered}
$$

If we assume that the evaporation losses have a negligible effect on the mass of water in the pool, and that the mass flow rates in and out of the pool are in balance, then the pool mass is essentially constant. In this case, the terms in the energy balance equation are:

$\underset{\text { energy in pool }}{\text { rate of change of }}=\frac{\mathrm{d}}{\mathrm{dt}} \mathrm{E}_{\text {pool }}=\frac{\mathrm{d}}{\mathrm{dt}}\left(\mathrm{mc}_{\mathrm{v}} \mathrm{T}_{\text {pool }}\right)=\mathrm{mc}_{\mathrm{v}} \frac{\mathrm{d}}{\mathrm{dt}} \mathrm{T}_{\text {pool }}$

$\begin{aligned} & \text { net rate of energy } \\ & \text { flow into the pool }\end{aligned}=\left.\left(\dot{\mathrm{m}}_{\mathrm{p}} \mathrm{c}_{\mathrm{p}} \mathrm{T}\right)\right|_{\text {in }}-\left.\left(\dot{\mathrm{m}}_{\mathrm{p}} \mathrm{c}_{\mathrm{p}} \mathrm{T}\right)\right|_{\text {out }}=\left.\dot{\mathrm{m}}_{\mathrm{p}} \mathrm{c}_{\mathrm{p}}\left(\mathrm{T}_{\text {in }}-\mathrm{T}_{\text {out }}\right)\right|_{\text {pool }}$

$\begin{aligned} & \text { internal generation rate } \\ & \text { of energy within the pool }\end{aligned}=\mathrm{P}_{\text {core }} \quad$ (where $\mathrm{P}_{\text {core }}$ is the operating power level of the core)

$\begin{gathered}\text { rate of energy loss at } \\ \text { surface of the pool }\end{gathered}=\mathrm{hA}\left(\mathrm{T}_{\text {pool }}-\mathrm{T}_{\text {air }}\right) \quad$ (where $\mathrm{h}$ is an effective heat transfer coefficient)

and, putting these terms into the above energy balance, with $\mathrm{c}=\mathrm{c}_{\mathrm{v}}=\mathrm{c}_{\mathrm{p}}$ for incompressible fluids, gives

$$
\mathrm{mc} \frac{\mathrm{dT}_{\text {pool }}}{\mathrm{dt}}=\left.\dot{\mathrm{m}}_{\mathrm{p}} \mathrm{c}\left(\mathrm{T}_{\text {in }}-\mathrm{T}_{\text {out }}\right)\right|_{\text {pool }}+\mathrm{P}_{\text {core }}-\mathrm{hA}\left(\mathrm{T}_{\text {pool }}-\mathrm{T}_{\text {air }}\right)
$$

or

$$
\frac{\mathrm{dT}_{\text {pool }}}{\mathrm{dt}}=\left.\frac{\dot{\mathrm{m}}_{\mathrm{p}}}{\mathrm{m}}\left(\mathrm{T}_{\text {in }}-\mathrm{T}_{\text {out }}\right)\right|_{\text {pool }}+\frac{1}{\mathrm{mc}} \mathrm{P}_{\text {core }}-\frac{\mathrm{hA}}{\mathrm{mc}}\left(\mathrm{T}_{\text {pool }}-\mathrm{T}_{\text {air }}\right)
$$

There are a number of approximations built into eqn. (2). Probably the most important consideration is that we have ignored any spatial dependence in the above development. Clearly the water temperature near the heat source (i.e. the reactor core) will be larger than the average pool temperature. In addition, the pool is physically quite large and it has rather complex internal flow patterns that differ significantly from the natural convection to the forced convection modes. Thus, by characterizing the pool energy content by a single average pool temperature, $\mathrm{T}_{\text {pool }}$, we are simply ignoring all this detail. However, even with the simplifications made here, we should be able to get a pretty good idea of how various factors affect the overall energy balance in this system.

Now, for the current project, we want to analyze this system under a specific set of conditions that lead to the Heat-Up of the UMLRR Pool. In particular, on March 25, 2004, the reactor was started up at about 9 am and operated at about $92 \%$ of rated power (i.e. $\mathrm{P}_{\text {core }} \approx 0.92 \mathrm{MW}$ ) for several hours under different conditions for the secondary side energy removal system. Of particular interest here is the early part of the experiment when the primary pump is turned on, but the secondary pump is off. With the secondary pump off, no energy is removed from the heat exchanger. Thus, the energy content of the coolant leaving the pool is essentially the same 
as that entering the pool or, for this case, $\left.\left(\mathrm{T}_{\text {in }}-\mathrm{T}_{\text {out }}\right)\right|_{\text {pool }} \approx 0$. In this mode of operation, the first term on the right hand side of eqn. (2) drops out, giving

$$
\frac{\mathrm{dT}_{\text {pool }}}{\mathrm{dt}}=\frac{1}{\mathrm{mc}} \mathrm{P}_{\text {core }}-\frac{\mathrm{hA}}{\mathrm{mc}}\left(\mathrm{T}_{\text {pool }}-\mathrm{T}_{\text {air }}\right) \quad \text { with } \quad \mathrm{T}_{\text {pool }}(0)=\mathrm{T}_{\mathrm{o}}
$$

This says that the pool temperature will increase because of the energy generated within by the reactor core and it can decrease because of losses at the pool surface. Since the surface losses are generally expected to be relatively small, we expect that the pool temperature will tend to increase -- thus, the emphasis on the Heat-Up of the UMLRR Pool.

Selected data from the actual experiment are displayed in Fig. 2. Here you can see that, for the first part of the experiment (from about 0.4 to 1.6 hours in the plot), all the temperature indicators increased nearly linearly since the constant production term (the energy generation within the core) completely dominated the energy loss terms. For example, notice that the pool inlet and outlet temperatures are nearly the same, indicating that negligible energy is removed from the primary coolant loop (secondary pump is off during this time period). Also, with the average pool temperature in the range of $73 \mathrm{~F}-78 \mathrm{~F}$ (the bottom curve in Fig. 2) and the containment air temperature near $75 \mathrm{~F}$, we would not expect much energy loss through the pool surface. Thus, all the pool/core temperature indicators are expected to rise -- just as observed in the actual experiment.

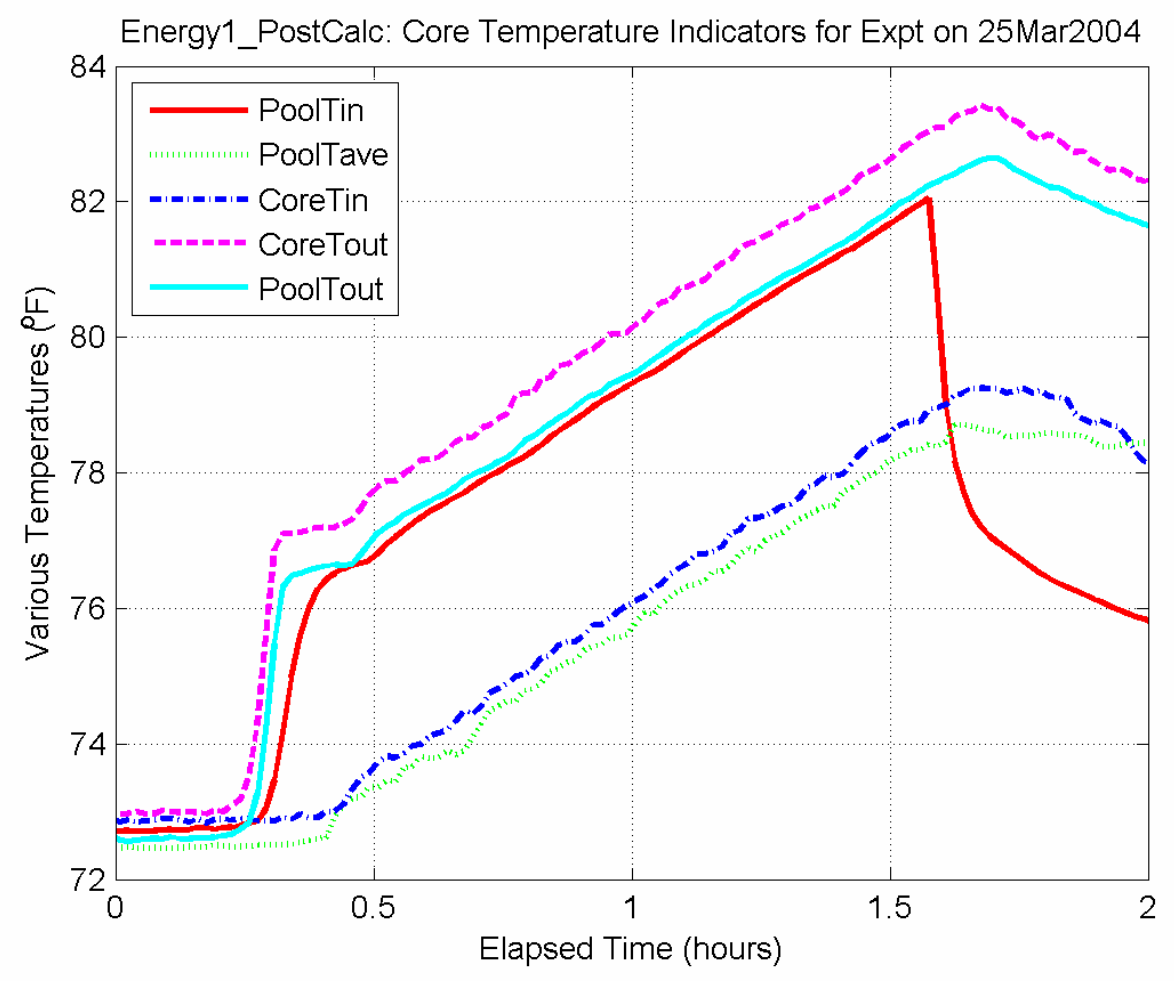

Fig. 2 Selected data for a portion of the UMLRR experiment on March 25, 2004. 


\section{Problem Description}

\section{Part $A$}

For the first part of your analysis, assume that the energy loss from the pool surface is small (assume that $\mathrm{hA} \rightarrow 0$ ). Solve the resultant initial value problem (IVP) from eqn. (3) with $\mathrm{T}_{\mathrm{o}}=73 \mathrm{~F}$ using the data in Table 1 to compute any needed constants for this situation. You should evaluate the pool heat-up rate $\left(\mathrm{dT}_{\text {pool }} / \mathrm{dt}\right)$ and the pool temperature profile versus time. Do these results compare with the actual experimental data for this portion of the experiment as shown in Fig. 2? Explain...

Note: For ease in comparing your analytical temperature profile to the measured data, a short Matlab file, tave_expt.m, containing the experimental data is available on the course website. You should use these data for evaluating the adequacy of the mathematical model for the Part A analysis.

\section{Part B}

For this part of the analysis, you should not ignore the surface loss term. In particular, you should solve the full IVP given in eqn. (3) using, as before, the data in Table 1 to evaluate the equation constants (be careful with units here). Evaluate and plot the resultant temperature profile assuming that the reactor is run in this mode ( $\mathrm{P}_{\text {core }}=0.92 \mathrm{MW}$ with the secondary off) for an 8-hour period (480 minutes). For comparison purposes, also plot the result of Part A over this same period (put the Part A and Part B results on the same curve).

Note that the heat transfer coefficient, $\mathrm{h}$, is quite sensitive to exact environmental conditions, and it can vary over a relatively wide range. In addition, it is really a time-dependent parameter, since the pool and containment air conditions vary with time. However, the actual computation of $\mathrm{h}$ from fundamental relationships is quite complicated and it can also complicate the overall mathematical model significantly (and all this is well beyond the scope of this project). Thus, to simplify the analysis here, we have decided to treat $\mathrm{h}$ as a constant and perform a sensitivity study to evaluate how relatively wide variations in h can affect the observed results. In particular, we will choose the nominal value of the effective heat transfer coefficient for the current analyses as $\mathrm{h}_{\text {nom }}=15 \mathrm{BTU} / \mathrm{hr}-\mathrm{ft}^{2}-\mathrm{F}$, and let this increase and decrease by a factor of 5 to address the effects of a high and low value, respectively.

Thus, for this part of the project, you need to solve the IVP associated with the full energy balance and evaluate and plot the result for three different values of $\mathrm{h}$ (for low, nominal, and high estimates). In doing all this, be sure to discuss your results in some detail. For example, do the two models, with and without surface losses, give similar behavior during the first hour or so? What about operation for a longer period of time? Also, what happens as the heat transfer coefficient is increased? Try to explain what is really happening here...

As a final evaluation, we note that the UMLRR has a Technical Specification that limits the pool temperature to about $108 \mathrm{~F}$ and, to assure that this is never exceeded, the practical operating limits are set below this value. For example, let's choose $100 \mathrm{~F}$ as the practical upper limit for the pool temperature. Based on this condition, and the two cases analyzed above, estimate how long the reactor could run under the current conditions, if the initial pool temperature is $73 \mathrm{~F}$. Does including the surface energy loss term make a large difference in this estimate? Explain... 


\section{Documentation}

Documentation for this problem should include a complete description of the problem to be solved, the details of the solution techniques, and the key results of your analyses including the requested plots and comparisons. Try to analyze and discuss the results in as much detail as possible. Also include, in an appendix, any program listings (or tabular data if using a spreadsheet) used in generating the summary plots.

This is a formal project and a professional report documenting your work is expected. Your report should have a brief Introduction that overviews the problem of interest, a Procedure section that discusses the problem formulation, the solution procedure, and any required derivations, and a Results section that summarizes the key results in tabular and/or graphical form, as appropriate. Be sure to thoroughly explain the logic used in your analysis and to fully discuss the results obtained.

This Project will be worth 50 points towards your HW grade in this course. Partial credit will be given for partially completed work, but only if significant progress towards a complete solution has been made. Team efforts with 3-4 students per team are encouraged for this project! Each team should only pass in a single, professional project report that is signed and dated by each team member, signifying that they contributed in a meaningful way to the final product. Each member of the team will receive the same grade.

Good luck and have fun -- this should be an interesting project!!!

Table 1 Numerical data for use in project calculations.

\begin{tabular}{|c|c|}
\hline Water Properties: & Operational Parameters (secondary off): \\
\hline density $=62.2 \mathrm{lbm} / \mathrm{ft}^{3}$ & core power $=0.92 \mathrm{MW}$ \\
\hline \multirow[t]{2}{*}{ specific heat $=1.0 \mathrm{BTU} / \mathrm{lbm}-\mathrm{F}$} & initial pool temperature $=73 \mathrm{~F}$ \\
\hline & containment air temperature $=75 \mathrm{~F}$ \\
\hline Pool Properties (approx.): & primary coolant flow rate $=1600 \mathrm{gpm}$ \\
\hline volume $=76000 \mathrm{gal}$ & $\left(T_{\text {in }}-T_{\text {out }}\right)_{\text {pool }}=-0.15 \mathrm{~F}$ (expt. data $)$ \\
\hline \multicolumn{2}{|l|}{ surface area $=500 \mathrm{ft}^{2}$} \\
\hline Heat Transfer Coeff. Sensitivity Study: & Conversion Factors: \\
\hline low $\mathrm{h}=3 \mathrm{BTU} / \mathrm{hr}-\mathrm{ft}^{2}-\mathrm{F}$ & $1 \mathrm{ft}^{3}=7.48 \mathrm{gal}$ \\
\hline nominal $\mathrm{h}=15 \mathrm{BTU} / \mathrm{hr}-\mathrm{ft}^{2}-\mathrm{F}$ & $1 \mathrm{MW}=1000 \mathrm{~kW}$ \\
\hline \multirow[t]{2}{*}{ high $\mathrm{h}=75 \mathrm{BTU} / \mathrm{hr}-\mathrm{ft}^{2}-\mathrm{F}$} & $1 \mathrm{~kW}=3412.14 \mathrm{BTU} / \mathrm{hr}$ \\
\hline & $1 \mathrm{hr}=60 \mathrm{~min}$ \\
\hline should let ti & $\begin{array}{l}\text { in minutes and, in general, be very } \\
\text { calculations. }\end{array}$ \\
\hline
\end{tabular}

